Research Article

\title{
Predicting the Ultimate Bearing Capacity of Bolts with an Optimized Function Model
}

\author{
Bin Zheng $\left(\mathbb{D},{ }^{1}\right.$ Jian Zhang, ${ }^{2}$ Tugen Feng $\mathbb{D},{ }^{2}$ and Maosen Cao ${ }^{1}$ \\ ${ }^{1}$ Department of Engineering Mechanics, Hohai University, Nanjing 210098, China \\ ${ }^{2}$ Key Laboratory of Ministry of Education for Geomechanics and Embankment Engineering, Hohai University, \\ Nanjing 210098, China \\ Correspondence should be addressed to Tugen Feng; tgfeng75@163.com
}

Received 6 January 2020; Revised 13 March 2020; Accepted 3 September 2020; Published 24 September 2020

Academic Editor: Claudio Mazzotti

Copyright (c) 2020 Bin Zheng et al. This is an open access article distributed under the Creative Commons Attribution License, which permits unrestricted use, distribution, and reproduction in any medium, provided the original work is properly cited.

\begin{abstract}
Bolts are widely employed as an effective ground reinforcement element to secure the underground workplaces. Due to their inherent accessibility, low cost, and easy implementation, rebar bolts are the most popular and commonly used reinforcement in ground support systems. However, it is expensive to obtain failure stage data from in situ pullout tests to study the ultimate bearing capacity of rebar bolts. In this paper, several function models that are commonly used for predicting the ultimate bearing capacity of bolts are presented. Based on these models, a general function model is constructed to replicate the relationship between the load and displacement of a rebar bolt in a pullout test. In addition, the value ranges of relevant parameters in the function model are also assessed. By analysing the general function model, an improved exponential and power function model, which is essential to bolt design, is presented to simulate the load-displacement curve and predict the ultimate bearing capacities of bolts. Comparisons between the improved exponential and power function model and other regular models show that the former has a higher calculation accuracy and good stability. Moreover, a comparison of the predicted ultimate bearing capacity and the test results indicates the reliability of the improved exponential and power function model. The improved exponential and power function model can provide theoretical guidance for the design of rebar bolts applied in reinforcement engineering.
\end{abstract}

\section{Introduction}

In civil and mining engineering, bolts are widely used to stabilize underground excavation operations owing to their high load-bearing capacity and low cost [1]. As the depth involved in rock mass engineering increases, the surrounding rock is subjected to more complicated geostresses $[2,3]$. The damage and failure of the bolts, such as through prestress loss, plate failure, and bolt shank rupture, have become substantial problems in deep underground engineering applications. Numerous field and experimental tests [4], theoretical analyses, and numerical simulations [5] have been conducted to analyse ground deformation and bolt fracture failures [6]. In addition, numerous studies have investigated the mechanical behaviors of rock-grout and grout-bolt interfaces [7]. Elastic wave analysis is a traditional nondestructive testing method used to investigate the mechanical behaviors of bolt interfaces. Starkey et al. [8] proposed the acoustic stress wave method, which can analyse large-area bolting systems based on the theory of the small-strain dynamic pile measurement technique [9]. Thruner [10] used the ultrasonic method to detect fully grouted bolts and obtained satisfactory results. However, the ultrasonic method is not suitable for long bolts because the ultrasonic wave attenuates during the propagation process. Compared with ultrasonic detection technology, ultrasonic guided waves have less attenuation and a longer propagation distance, thereby providing good application prospects in nondestructive tests. Zhang et al. [11] used guided waves to detect anchorage quality and determined the optimal excitation frequency. Moreover, they established a correlation between cement solidification time and wave velocity. The 
aforementioned studies significantly contributed to developing methods by which to evaluate the condition of bolting systems; however, these studies did not involve ultimate bearing capacity predictions.

The ultimate bearing capacity of a bolt is influenced by the anchorage quality [12], rock/soil-induced stress changes [13], bolt diameter [14], grout properties [15], bar shape [16], and embedment length [17]. However, the ultimate bearing capacity of a bolt is not clearly understood and, to some extent, the basis for bolting design is still empirical or semiempirical [18].

Based on the anchor pullout mechanism, the ultimate bearing capacity of a bolt is mainly composed of the bond stress of the grout and the friction force of the rock-bolt interface (Figure 1). Chen [19] proposed a formula for calculating the ultimate bearing capacity of an expanded bolt in sand. Zhuang et al. [20] presented formulas for the ultimate bearing capacity of a single bolt and for groups of bolts. Nevertheless, the application scope of the above formulas is limited due to geotechnical plastic limit balance theory. Therefore, a destructive experiment is needed in order to obtain an accurate value of the ultimate bearing capacity of a bolt.

A pullout test is a common destructive experiment used to obtain the curves of bolt static load $(P)$ and displacement $(S)$, as shown in Figure 2. The test results show that the tensile load of a bolt increases to the peak value when the axial displacement is very small and then decreases to the residual value with the further increase of the axial displacement [21]. Long [22] proposed hyperbolic and exponential models to simulate the $P-S$ curve of a pullout test and predict the ultimate bearing capacity of a bolt. Later, Jiang et al. [23] modified the hyperbolic model and proposed adjusted and corrected hyperbolic models, which provided increased prediction accuracies in some cases. However, the empirical parameters used in the theoretical calculation methods are inconsistent with the actual parameters. Zhao [22] established an optimal combined prediction model, which is composed of hyperbolic and exponential models. Following a similar approach, Tu et al. [24] combined hyperbolic and exponential models to predict the ultimate bearing capacity of a single pile, in which they noted that the weight of the exponential model was greater than that of the hyperbolic model in most circumstances. Hyperbolic and exponential models are two special cases of a power model, which is more suitable for simulating the load-displacement curve of a pile [25].

Due to the complexity of the reinforcement objects and the diversity of the anchorage modes, there is still no unified understanding in the research of the pull-load transfer mechanism of bolts. No calculation methods can precisely describe the stress distribution evolution of a bolt effectively, and the methods have difficulty reflecting the nonlinear characteristics of bolt-interface shear slipping. Due to the lack of necessary connections and transformations between theoretical analyses and engineering measurements, the results of the theoretical analyses and engineering measurements are quite different and cannot accurately meet the needs of practical engineering. At present, most anchorage

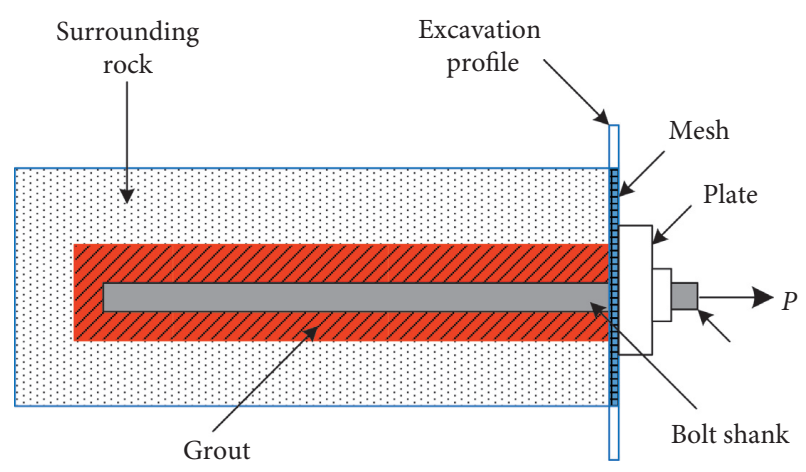

Figure 1: Schematic diagram of a pullout test.

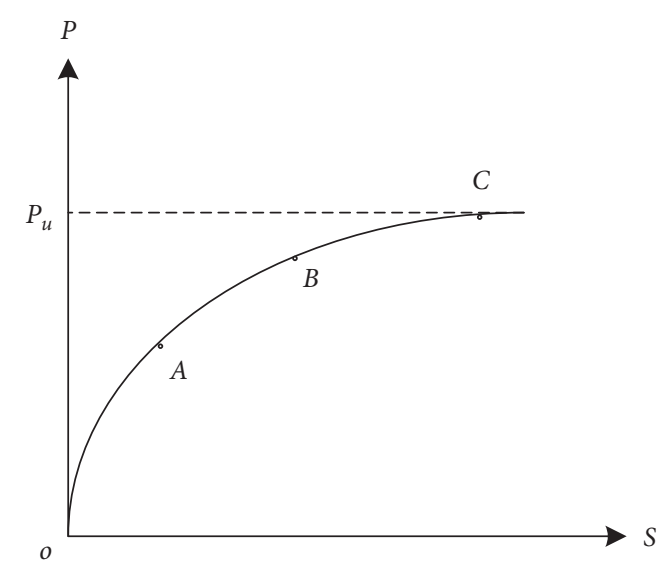

FIGURE 2: Schematic diagram of the load-displacement response of a bolt.

projects still rely on analogy methods or semiempirical and semitheoretical methods for design and construction, which leads to waste in some projects due to a design strength of the bolt that is too high, or to hidden dangers in some projects due to design strength of the bolt that is too low for safety construction. Therefore, the prediction of the ultimate bearing capacity of bolts needs further research.

The anchoring strata studied in this paper are gravel sand viscous soil, middle coarse sand mixed clay, and granite residual soil. In this case, it is a fully grouted bolt and the bolt can resist the upward displacement of the buildings on it. It is related to the height and change of the underground water level. The length of the bolt ranges from 6 to $15 \mathrm{~m}$, and the diameter of the bolt grouts ranges from 150 to $180 \mathrm{~mm}$. The anchor bars are $32 \mathrm{~mm}$ threaded rebars. The holes are drilled and injected with pure cement mud under normal pressure conditions. The ultimate bearing capacity of the bolt is predicted by an optimized function model with limited measured data from pullout tests. Some practical cases of pullout tests are analysed to verify the validity of the model.

The rest of the paper is organized as follows. In Section 2 , we briefly discuss the basic concept of the function model used for simulating $P-S$ curves. In Section 3, to demonstrate the effectiveness of the model, the model predictions are compared with pullout test results from the literature. 
In the last section, a summary and conclusions are provided.

\section{Function Model}

In the pullout test, firstly, piercing Jack is set on the test bolt bar, and then the upper part is welded to the steel plate or steel bar. The base acts on the ground through small steel beam and pressure plate platform. Finally, the electric oil pump is used to pressurize the Jack and load in stages. The criterion for the end-loading of the test is that the displacement of the anchor head does not converge, and the criterion for the failure of the bolt is that the displacement increment under a load is twice that of the previous stage. The ultimate bearing capacity is the load in the stage prior to that when the bolt is damaged.

There are three stages during the pullout process of a bolt: the elastic stage, elastic-plastic stage, and failure stage. As shown in Figure 2, the theoretical $P-S$ curve of a bolt has five characteristics: crossing origin, nonnegative boundedness, monotonical increase, infinite convergence, and convexity. Thus, a reasonable function model used to simulate $P-S$ curve of a bolt should satisfy the above features. Hyperbolic, adjusted hyperbolic, corrected hyperbolic, exponential, and power function models have often been used to simulate the $P-S$ curves of bolts [22]. Through a comprehensive analysis of the characteristics of exponential, hyperbolic, and power function models, it can be found that they all have the same structure, which is expressed as

$$
P=P_{u}\left[1-\frac{x}{f(S)}\right]
$$

where $P_{u}$ is the ultimate bearing capacity, $x$ is an unknown parameter, and $f(S)$ is the function factor, which is not equal to zero. Assuming that $f(S)=S+a$ and $x=a$ in equation (1), the hyperbolic model can be obtained. The criteria for exponential model design are $f(S)=e^{a S}$ and $x=1$. Moreover, the power function model is obtained when $f(S)=(1+a S)^{b}$ and $x=1$. Therefore, equation (1) can be regarded as a general function model to simulate the $P-S$ curve of a bolt.

As mentioned above, equation (1) needs to cross the origin, have nonnegative boundedness, monotonically increase, have infinite convergence, and exhibit convexity. These characteristics are analysed hereafter.

(1) Crossing the origin: $S$ is equal to zero when $1-x /$ $f(S)=0$, which stipulates that $f(0)=x \neq 0$.

(2) Nonnegative boundedness: let $0 \leq 1-x /(S) \leq 1$ in equation (1), which represents the state that satisfies this condition.

(3) Monotonical increase: differentiating equation (1) with respect to $S$ and letting the result be greater than or equal to zero yields $\mathrm{d} P / \mathrm{d} S=[\mathrm{Pu}(1-x)$ $f(S))]^{\prime}=-P_{u} \cdot x \cdot f^{\prime}(S) / f 2(S) \geq 0$.

(4) Infinite convergence: given $\lim _{S \longrightarrow \infty}(x / f(S))=0$, the load $P$ approaches the ultimate bearing capacity $P_{u}$ as the displacement $S$ increases.
(5) Convexity: the load-displacement curve should be continuous and exhibit convexity, which stipulates that equation (1) must satisfy

$$
\begin{aligned}
\frac{\mathrm{d}^{2} P}{\mathrm{~d} S^{2}} & =\left[P_{u}\left(1-\frac{x}{f(S)}\right)\right]^{\prime \prime}=P_{u} \cdot x \cdot\left(\frac{f^{\prime}(S)}{f^{2}(S)}\right)^{\prime} \\
& =P_{u} \cdot x \cdot \frac{f^{\prime \prime}(S) \cdot f(S)-2 f^{\prime 2}(S)}{f^{3}(S)} \\
& =P_{u} \cdot \frac{x}{f(S)} \cdot\left[\frac{f^{\prime \prime}(S)}{f(S)}-\frac{2 f^{\prime 2}(S)}{f^{2}(S)}\right] \leq 0,
\end{aligned}
$$

that is,

$$
\frac{f^{\prime \prime}(S)}{f(S)} \leq 2\left[\frac{f^{\prime}(S)}{f(S)}\right]^{2} .
$$

Based on the above analysis, it can be concluded that the function factor $f(S)$ should satisfy the following equation:

$$
\left\{\begin{array}{l}
f(0)=x \neq 0, \\
0<\left(\frac{x}{f(S)}\right) \leq 1, \\
\lim _{S \longrightarrow \infty} f(S)=\infty, \\
x \cdot f^{\prime}(S) \geq 0, \\
S \geq 0, \quad f(S) \neq 0, \\
\frac{f^{\prime \prime}(S)}{f(S)} \leq 2\left[\frac{f^{\prime}(S)}{f(S)}\right]^{2} .
\end{array}\right.
$$

Equation (4) is used to select the function factor for real applications. Note that the actual $P-S$ curve of a bolt exhibits convexity overall, but there may be local concave points. Therefore, the last item in equation (4) is only used as an auxiliary condition.

Previous studies have used hyperbolic, exponential, and power function models to simulate $P-S$ curves [22]. The adjusted hyperbolic $(A H)$ model, which is an improved version of the original hyperbolic model, has extensive applicability. The equation of this model is

$$
P=P_{u} \frac{S}{S+\left(a S /\left(S^{1.5}+S_{n-1}\right)\right)+b},
$$

where $P$ is the load, $S$ denotes the bolt displacement, $S_{n-1}$ represents the measured displacement under the load in the previous stage, and $a$ and $b$ are unknown parameters to be determined.

The corrected hyperbolic $(\mathrm{CH})$ model is also based on the hyperbolic model. This model satisfies 


$$
P=P_{u} \frac{S}{a+S+b S^{c}}
$$

where $b S^{c}$ represents a regulator.

The accuracy of the exponential model is poor. Hence, in this paper, we use the general function model, shown in equation (1), to obtain the improved exponential (IE) model:

$$
P=P_{u}\left(1-\frac{1+k}{e^{a S}+k}\right),
$$

where $a$ and $k$ are unknown parameters.

To some extent, the introduction of other functions can improve the accuracy and the adjustment range of a single model. Furthermore, the coordinated combination of different function models enables the simulated curve to more closely approximate the actual values. Equation (4) was used to select appropriate factors to construct an improved exponential and power function (IEPF) model, which was used to simulate the load-displacement curve of a pile [18]:

$$
P=P_{u}\left[1-\frac{1+k}{e^{a s}+k}(b S+1)^{c}\right],
$$

where $a, b, c$, and $k$ are fitting parameters. The precision of the IEPF model is higher than that of IE model [25]. In this paper, we applied the IEPF model, an optimized function model, to predict the ultimate bearing capacity of a bolt.

The parameters of the $A H$ model were determined through regression analysis. The rest of the models followed the principle that the sum of the squared errors (SSE) should be minimized. The fmincon function in MATLAB was used for parameter fitting.

The simulation results were evaluated using the accuracy, stability, and precision of the ultimate bearing capacity prediction for a bolt. Accuracy was measured by the absolute $S S E$ and standard error (SE). Stability was evaluated by pure mean square error ( $S S P E)$ and relative standard error ( $S P E)$. Relative error (SS) was used as a precision measure for the ultimate bearing capacity prediction of a bolt:

$$
\begin{aligned}
\mathrm{SSE} & =\sum_{i=1}^{N}\left(P_{i}^{\prime}-P_{i}\right)^{2}, \\
\mathrm{SSPE} & =\sum_{i=1}^{N}\left[\frac{P_{i}^{\prime}-P_{i}}{P_{i}}\right]^{2}, \\
\mathrm{SE} & =\sqrt{\frac{1}{N} \sum_{i=1}^{N}\left(P_{i}^{\prime}-P_{i}\right)^{2},} \\
\mathrm{SPE} & =\sqrt{\frac{1}{N} \sum_{i=1}^{N}\left[\frac{P_{i}^{\prime}-P_{i}}{P_{i}}\right]^{2},} \\
\mathrm{SS} & =\frac{P_{u}^{\prime}-P_{u}}{P_{u}} \times 100 \%,
\end{aligned}
$$

where $N$ is the number of measured data; $P_{i}^{\prime}$ and $P_{i}$ represent the predicted and measured values of bearing capacity, respectively; $P_{u}^{\prime}$ denotes the predicted ultimate bearing capacity; and $P_{u}$ is the test value.

\section{Numerical Results}

To verify the rationality of the proposed function models, the load-displacement results of bolts from four field tests in the literature are presented hereafter.

3.1. Example 1. In example 1, experimental in situ pullout tests on $12 \mathrm{~m}$ long and $15 \mathrm{~m}$ long bolts conducted by Wang et al. [26] are presented. The material properties of the bolts are $L_{A 1}=12 \mathrm{~m}, L_{A 2}=15 \mathrm{~m}$ ( $L$ is the length of the bolt), $r_{A 1}=r_{A 2}=32 \mathrm{~mm} \mathrm{(} r$ is the radius of the bolt), and $r_{g}=180 \mathrm{~mm}\left(r_{g}\right.$ is the radius of the grout). The anchorage stratum is granite residual soil and the grouting material is cement. The test results are listed in Table 1, in which $P$ is the applied load and $S_{A 1}$ and $S_{A 2}$ represent the displacement of bolts $A_{1}$ and $A_{2}$ under the applied load in each stage, respectively. Using equations (5)-(8) to fit the experimental results, the derived parameters are shown in Table 2. Additionally, the prediction of the load-displacement profile using these parameters is illustrated in Figures 3 and 4. It is clear that predictions from each model closely approximate the experimental results. Table 3 shows that the accuracy of the $A H$ and IEPF models is high and that the accuracy of the $I E$ model is poor. In Table 4, each model exhibits good stability. Table 5 shows the prediction results from each model for the ultimate bearing capacity of the bolts. The results show that the IE and IEPF models provide closer approximations of the experimental data.

3.2. Example 2. Wang et al. [26] conducted pullout tests of $6 \mathrm{~m}$ long and $32 \mathrm{~mm}$ diameter bolts buried in the gravel sand viscous soil and middle coarse sand mixed clay. The grouting material was cement. The practical load-displacement results are listed in Table 6 , in which $S_{B 1}$ and $S_{B 2}$ represent the displacement of bolts $B_{1}$ and $B_{2}$ under the applied load $P$ in each stage, respectively. The parameters displayed in Table 7 were calculated by fitting equations (5)-(8) to match the experimental data shown in Figures 5 and 6. As shown in Figures 5 and 6, all models reasonably approximate the experimental results except the IE model. Tables 8 and 9 illustrate the accuracy and stability of each model. In Table 8, the accuracy of the IEPF model for bolt $B_{1}$ is high. Moreover, there is high accuracy between the $\mathrm{CH}$ model and the experimental data for bolt $B_{2}$. In Table 9, the $C H$ and IEPF models exhibit good stability. As shown in Table 10, the IEPF model can predict the ultimate bearing capacity of the two bolts well.

3.3. Example 3. An in situ pullout test of a novel steel-strand rock bolt was recently conducted by Liu and Yang [27]. The test load-displacement data are listed in Table 11, in which $S_{C 1}$ and $S_{C 2}$ are the displacements of bolts $C_{1}$ and $C_{2}$ under the applied load $P$ in each stage, respectively. The parameters 
Table 1: Pullout test results from example 1.

\begin{tabular}{lccc}
\hline No. & $\mathrm{P}(\mathrm{kN})$ & $\mathrm{S}_{A 1}(\mathrm{~mm})$ & $\mathrm{S}_{A 2}(\mathrm{~mm})$ \\
\hline 1 & 70 & 0.6 & 0.37 \\
2 & 210 & 2.19 & 2.11 \\
3 & 350 & 4.86 & 5.72 \\
4 & 420 & 6.82 & 8.99 \\
5 & 490 & 8.85 & 13.68 \\
6 & 560 & 20.55 & 17.07 \\
7 & 595 & 23.82 & 19.67 \\
8 & 630 & 29.24 & 24.13 \\
9 & 665 & 40.63 & 39.19 \\
\hline
\end{tabular}

TABle 2: Model parameters for example 1.

\begin{tabular}{lcccc}
\hline Bolt & AH & CH & IE & IEPF \\
\hline$A_{1}$ & $a=-5.45$ & $a=-5.77$ & $a=0.07$ & $a=-16.79$ \\
$A_{2}$ & $b=5.70$ & $b=11.39$ & $k=-0.63$ & $b=0.09$ \\
& $a=22.45$ & $c=-0.02$ & $a=2.1 \times 10^{-3}$ & $c=-1.96$ \\
& $b=4.21$ & $a=7.51$ & $k=-0.99$ & $k=-302.10$ \\
& & $b=-0.85$ & & $a=0.13$ \\
& & $c=-1.46$ & & $b=5.48$ \\
& & & & $c=0.89$ \\
& & & & $k=-0.98$ \\
\hline
\end{tabular}

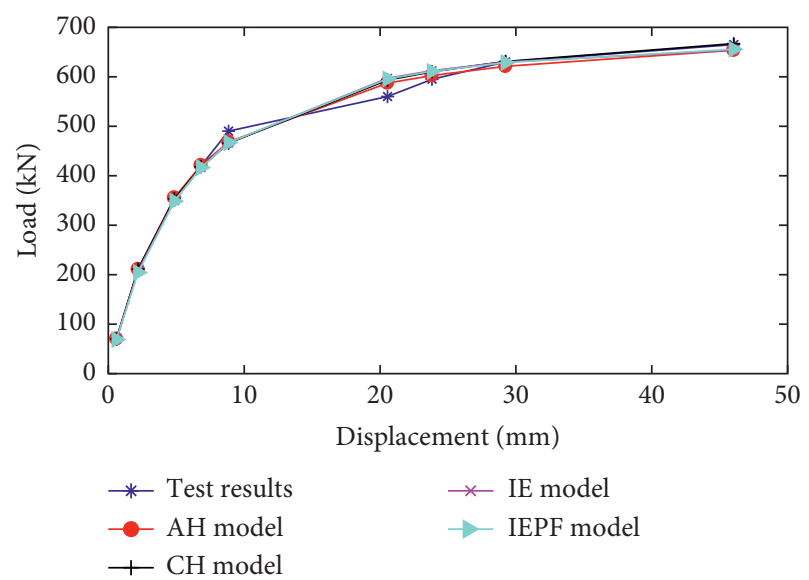

Figure 3: Comparison of each model with the test data from $A_{1}$.

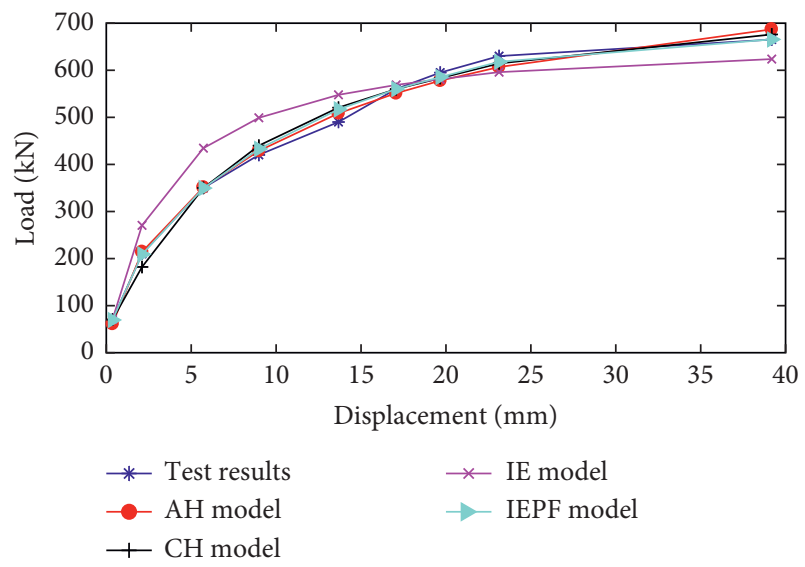

Figure 4: Comparison of each model with the test data from $A_{2}$.
TABle 3: Accuracy of each model for example 1.

\begin{tabular}{lcccc}
\hline Model & $\mathrm{SSE}_{A 1}$ & $\mathrm{SE}_{A 1}$ & $\mathrm{SSE}_{A 2}$ & $\mathrm{SE}_{A 2}$ \\
\hline $\mathrm{AH}$ & 1513 & 12.97 & 1902 & 14.54 \\
$\mathrm{CH}$ & 1936 & 14.67 & 2601 & 17.01 \\
$\mathrm{IE}$ & 2336 & 16.11 & 2351 & 51.11 \\
$\mathrm{IEPF}$ & 2179 & 15.56 & 1127 & 11.19 \\
\hline
\end{tabular}

TABLe 4: Stability of each model for example 1.

\begin{tabular}{lcccc}
\hline Model & SSPE $_{A 1}$ & SPE $_{A 1}$ & SSPE $_{A 2}$ & SPE $_{A 2}$ \\
\hline AH & $5.3 \times 10^{-3}$ & $2.42 \times 10^{-2}$ & $2.04 \times 10^{-2}$ & $4.76 \times 10^{-2}$ \\
CH & $6.8 \times 10^{-3}$ & $2.74 \times 10^{-2}$ & $2.5 \times 10^{-2}$ & $5.28 \times 10^{-2}$ \\
IE & $7.9 \times 10^{-3}$ & $2.96 \times 10^{-2}$ & $1.98 \times 10^{-2}$ & 0.15 \\
IEPF & $8.1 \times 10^{-3}$ & $3.01 \times 10^{-2}$ & $4.7 \times 10^{-3}$ & $2.27 \times 10^{-2}$ \\
\hline
\end{tabular}

TABLE 5: Ultimate bearing capacity prediction for example 1.

\begin{tabular}{lcccc}
\hline Model & Prediction $_{A 1}$ & Error $_{A 1}(\%)$ & Prediction $_{A 2}$ & Error $_{A 2}(\%)$ \\
\hline AH & 724.11 & 8.76 & 817.72 & 19.72 \\
CH & 736.18 & 10.57 & 805.43 & 17.93 \\
IF & 663.39 & -0.36 & 675.78 & -1.06 \\
IEPF & 682.99 & 2.58 & 678.28 & -0.69 \\
\hline
\end{tabular}

TABLe 6: Pullout test results from example 2.

\begin{tabular}{lccc}
\hline No. & $\mathrm{P}(\mathrm{kN})$ & $\mathrm{S}_{B 1}(\mathrm{~mm})$ & $\mathrm{S}_{B 2}(\mathrm{~mm})$ \\
\hline 1 & 55 & 0.6 & 0.1 \\
2 & 165 & 4.5 & 4.3 \\
3 & 275 & 9.5 & 10.6 \\
4 & 330 & 13.7 & 14.9 \\
5 & 368 & - & - \\
6 & 385 & 22.7 & - \\
7 & 418 & - & 31.8 \\
\hline
\end{tabular}

TABle 7: Model parameters for example 2.

\begin{tabular}{lcccc}
\hline Bolt & AH & CH & IE & IEPF \\
\hline$B_{1}$ & $a=22.49$ & $a=9.18$ & $a=6 \times 10^{-3}$ & $a=0.20$ \\
$B_{2}$ & $b=5.03$ & $b=-0.83$ & $k=-0.98$ & $b=7.32$ \\
& $a=53.24$ & $c=-3.02$ & $a=1.4 \times 10^{-3}$ & $c=-0.07$ \\
& $b=0.66$ & $a=14.22$ & $k=-0.99$ & $k=-3.38$ \\
& & $b=-5.40$ & & $a=0.16$ \\
& & $c=-0.39$ & & $b=24.76$ \\
& & & & $c=-0.11$ \\
& & & & $k=6.99$ \\
\hline
\end{tabular}

calibrated following the above procedure are listed in $\mathrm{Ta}$ ble 12 . The predicted load-displacement curves using these parameters are plotted in Figures 7 and 8. It is clear that each model closely approximates the experimental results. Tables 13 and 14 illustrate the accuracy and stability of each model. In Table 13, the accuracy of the $\mathrm{CH}$ and IEPF models for bolt $C_{1}$ is high. The accuracy of the $\mathrm{CH}$ model for bolt $\mathrm{C}_{2}$ is high. In Table 14, the $C H$ and IEPF models exhibit good stability. Table 15 displays the prediction results from each 


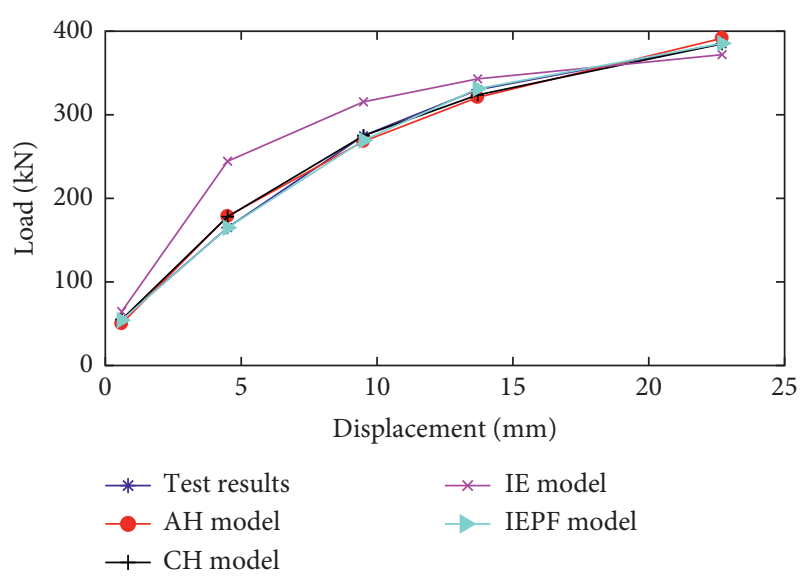

FIgURE 5: Comparison of each model with the test data from $B_{1}$.

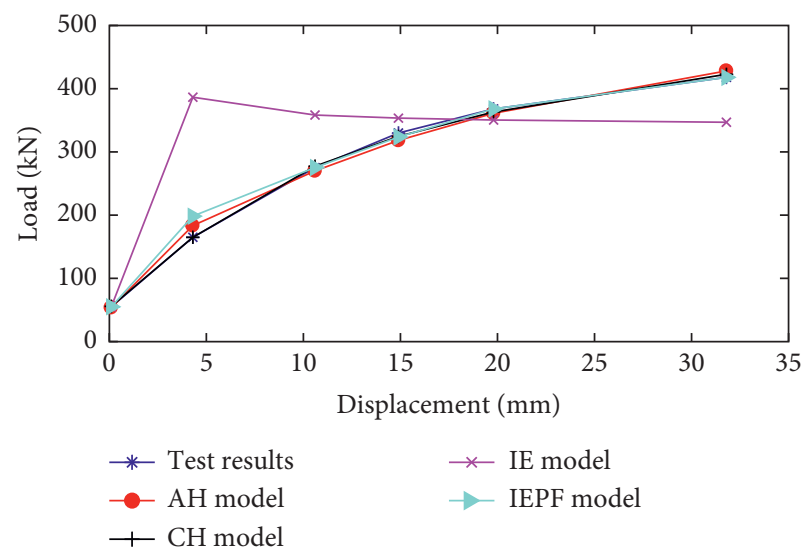

Figure 6: Comparison of each model with the test data from $B_{2}$.

TABle 8: Accuracy of each model for example 2.

\begin{tabular}{lcccc}
\hline Model & $\mathrm{SSE}_{B 1}$ & $\mathrm{SE}_{B 1}$ & $\mathrm{SSE}_{B 2}$ & $\mathrm{SE}_{B 2}$ \\
\hline $\mathrm{AH}$ & 377.96 & 8.69 & 651.26 & 10.42 \\
$\mathrm{CH}$ & 207.28 & 6.44 & 81.68 & 3.69 \\
$\mathrm{IE}$ & 8356 & 30.47 & $6.19 \times 10^{4}$ & 101.59 \\
$\mathrm{IEPF}$ & 32.68 & 2.56 & 1152 & 13.85 \\
\hline
\end{tabular}

TABle 9: Stability of each model for example 2.

\begin{tabular}{lcccc}
\hline Model & $\mathrm{SSPE}_{B 1}$ & $\mathrm{SPE}_{B 1}$ & $\mathrm{SSPE}_{B 2}$ & $\mathrm{SPE}_{B 2}$ \\
\hline $\mathrm{AH}$ & $1.59 \times 10^{-2}$ & $5.65 \times 10^{-2}$ & $1.6 \times 10^{-2}$ & $5.1 \times 10^{-2}$ \\
$\mathrm{CH}$ & $6.5 \times 10^{-3}$ & $3.62 \times 10^{-2}$ & $8.21 \times 10^{-4}$ & $1.17 \times 10^{-2}$ \\
IE & 0.29 & 0.18 & 1.93 & 0.57 \\
IEPF & $5.85 \times 10^{-4}$ & $1.08 \times 10^{-2}$ & $4.12 \times 10^{-2}$ & $8.28 \times 10^{-2}$ \\
\hline
\end{tabular}

TABLE 10: Ultimate bearing capacity prediction for example 2.

\begin{tabular}{lcccc}
\hline Model & Prediction $_{B 1}$ & Error $_{B 1}(\%)$ & Prediction $_{B 2}$ & Error $_{B 2}(\%)$ \\
\hline $\mathrm{AH}$ & 550.59 & 43.01 & 551.41 & 31.92 \\
$\mathrm{CH}$ & 540.68 & 40.44 & 593.21 & 41.92 \\
$\mathrm{IF}$ & 422.92 & 9.85 & 341.42 & -18.32 \\
$\mathrm{IEPF}$ & 398.06 & 3.39 & 429.42 & 2.73 \\
\hline
\end{tabular}

TABLE 11: Pullout test results from example 3.

\begin{tabular}{lccc}
\hline No. & $\mathrm{P}(\mathrm{kN})$ & $\mathrm{S}_{C 1}(\mathrm{~mm})$ & $\mathrm{S}_{C 2}(\mathrm{~mm})$ \\
\hline 1 & 15 & 1.11 & 1.28 \\
2 & 30 & 1.48 & 1.67 \\
3 & 45 & 1.90 & 2.10 \\
4 & 60 & 2.32 & 2.58 \\
5 & 75 & 2.84 & 3.10 \\
6 & 90 & 3.42 & 3.78 \\
7 & 105 & 4.12 & 4.50 \\
8 & 120 & 5.10 & 5.48 \\
9 & 135 & 6.24 & 6.68 \\
10 & 150 & 7.90 & 8.36 \\
\hline
\end{tabular}

TABLE 12: Model parameters for example 3.

\begin{tabular}{lcccc}
\hline Bolt & AH & CH & IE & IEPF \\
\hline$C_{1}$ & $a=-50.31$ & $a=5.36$ & $a=1.02$ & $a=0.33$ \\
$C_{2}$ & $b=21.02$ & $b=15.77$ & $k=16.47$ & $b=2.77$ \\
& $a=-69.18$ & $c=-2.36$ & $a=0.96$ & $c=0.49$ \\
& $b=27.90$ & $a=6.01$ & $k=18.97$ & $k=-0.62$ \\
& $b=27.61$ & & $a=0.48$ \\
& & $c=-2.49$ & & $b=1.16$ \\
& & & & $c=0.78$ \\
& & & & $k=-0.32$ \\
\hline
\end{tabular}

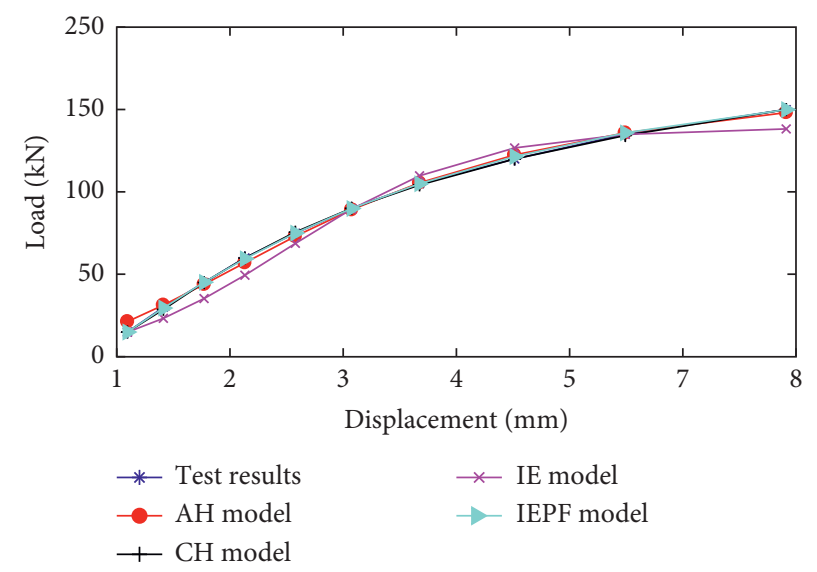

Figure 7: Comparison of each model with the test data from $C_{1}$.

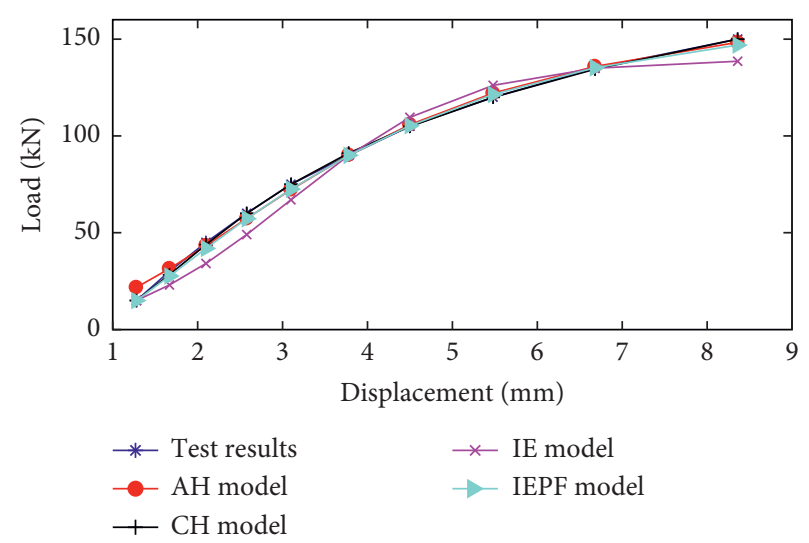

FIgURE 8: Comparison of each model with the test data from $C_{2}$. 
TABLE 13: Accuracy of each model for example 3.

\begin{tabular}{lcccc}
\hline Model & $\mathrm{SSE}_{C 1}$ & $\mathrm{SE}_{C 1}$ & $\mathrm{SSE}_{C 2}$ & $\mathrm{SE}_{C 2}$ \\
\hline $\mathrm{AH}$ & 66.69 & 2.58 & 73.86 & 2.72 \\
$\mathrm{CH}$ & 3.13 & 0.56 & 5.84 & 0.76 \\
$\mathrm{IE}$ & 495.77 & 7.04 & 541.19 & 7.36 \\
$\mathrm{IEPF}$ & 3.61 & 0.60 & 40.24 & 2.01 \\
\hline
\end{tabular}

TABLE 14: Stability of each model for example 3.

\begin{tabular}{lcccc}
\hline Model & SSPE $_{C 1}$ & SPE $_{C 1}$ & SSPE $_{C 2}$ & SPE $_{C 2}$ \\
\hline AH & 0.18 & 0.14 & 0.21 & 0.15 \\
CH & $2.0 \times 10^{-3}$ & $1.4 \times 10^{-2}$ & $4.1 \times 10^{-3}$ & $2.02 \times 10^{-2}$ \\
IE & 0.15 & 0.12 & 0.17 & 0.13 \\
IEPF & $5.35 \times 10^{-4}$ & $7.3 \times 10^{-3}$ & $1.46 \times 10^{-2}$ & $3.83 \times 10^{-2}$ \\
\hline
\end{tabular}

TABLE 15: Ultimate bearing capacity prediction for example 3.

\begin{tabular}{lcccc}
\hline Model & Prediction $_{C 1}$ & Error $_{C 1}(\%)$ & Prediction $_{C 2}$ & Error $_{C 2}(\%)$ \\
\hline AH & 280.36 & 82.64 & 310.69 & 96.77 \\
CH & 254.06 & 65.51 & 260.36 & 69.62 \\
IF & 138.98 & -9.46 & 139.51 & -9.12 \\
IEPF & 173.25 & 12.87 & 159.57 & 3.96 \\
\hline
\end{tabular}

model for the ultimate bearing capacity of the bolts. The results show that the IF model provides the closest approximation of the experimental data of bolt $C_{1}$ and that the $I E P F$ model can predict the ultimate bearing capacity of bolt $C_{2}$ well.

3.4. Example 4. Wang et al. [26] carried out pullout tests of a steel-strand inserted in cement to simulate and study the mechanical behavior of the bolt-rock interface. The anchorage strata were gravel sand viscous soil and middle coarse sand mixed clay. The geometrical properties of the bolts were $r_{b}=32 \mathrm{~mm}$ ( $r_{b}$ is the radius of the bolt), $r_{g}=150 \mathrm{~mm}\left(r_{g}\right.$ is the radius of the grout), and $L=10 \mathrm{~m}(L$ is the length of the bolt). The test results are listed in Table 16, in which $S_{D 1}$ and $S_{D 2}$ denote the displacement of bolts $D_{1}$ and $D_{2}$ under the applied load $P$ in each stage, respectively. The parameters used for the pullout test, which were calculated with equations (5)-(8), are listed in Table 17. The analytical predictions of the load-displacement relation are plotted in Figures 9 and 10, in which the test results are also included for comparison. It is clear that each model closely approximated the experimental results. Tables 18 and 19 illustrate the accuracy and stability of each model. As shown in Table 18, the accuracy of the IEPF model for the two bolts is high. In Table 19, the IEPF model exhibits the best stability. Table 20 compares the test results and the analytical predictions of the ultimate bearing capacity of the bolts. The IEPF model provides the best ultimate bearing capacity predictions for the bolts.

\section{Discussion}

In this paper, it should be noted that the parameters of the function model are obtained by the fitting of situ pullout test
Table 16: Pullout test results from example 4.

\begin{tabular}{lcccc}
\hline No. & $\mathrm{P}_{D 1}(\mathrm{kN})$ & $\mathrm{S}_{D 1}(\mathrm{~mm})$ & $\mathrm{P}_{D 2}(\mathrm{~mm})$ & $\mathrm{S}_{D 2}(\mathrm{~mm})$ \\
\hline 1 & 55 & 1.0 & 55 & 1.6 \\
2 & 165 & 5.2 & 165 & 5.5 \\
3 & 275 & 9.5 & 275 & 10.2 \\
4 & 385 & 11.4 & 330 & 13.5 \\
5 & 440 & 14.9 & 385 & 15.5 \\
6 & 495 & 17.2 & 440 & 18.5 \\
7 & 550 & 20.6 & 533 & 21.0 \\
8 & 583 & 24.7 & 583 & 37.3 \\
9 & 615 & 34 & - & - \\
\hline
\end{tabular}

TABLE 17: Model parameters for example 4.

\begin{tabular}{ccccc}
\hline Bolt & AH & CH & IE & IEPF \\
\hline$D_{1}$ & $\mathrm{a}=-292.1$ & $\mathrm{a}=23.4$ & $\mathrm{a}=3.73 \times 10-2$ & $\mathrm{a}=-10.93$ \\
$D_{2}$ & $\mathrm{~b}=82.4$ & $\mathrm{~b}=-3.7$ & $\mathrm{k}=-0.54$ & $\mathrm{~b}=-0.03$ \\
& $a=-114.6$ & $c=-66.3$ & $a=6.27 \times 10^{-2}$ & $c=1.95$ \\
& $b=50.3$ & $a=27.2$ & $k=0.15$ & $k=-32.08$ \\
& & $b=49.5$ & & $a=0.19$ \\
& & $c=-9.6$ & & $b=3.39 \times 10^{-2}$ \\
& & & & $c=-1.72$ \\
& & & & $k=45.99$ \\
\hline
\end{tabular}

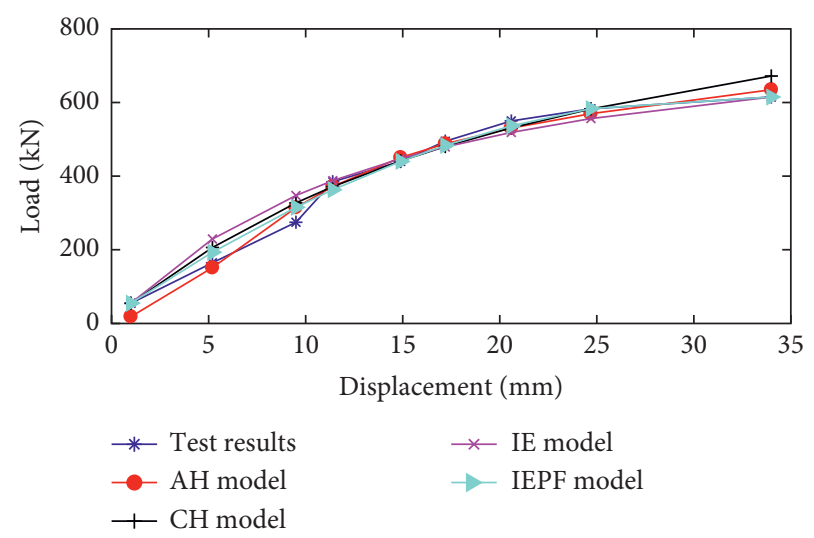

Figure 9: Comparison of each model with the test data from $D_{1}$.

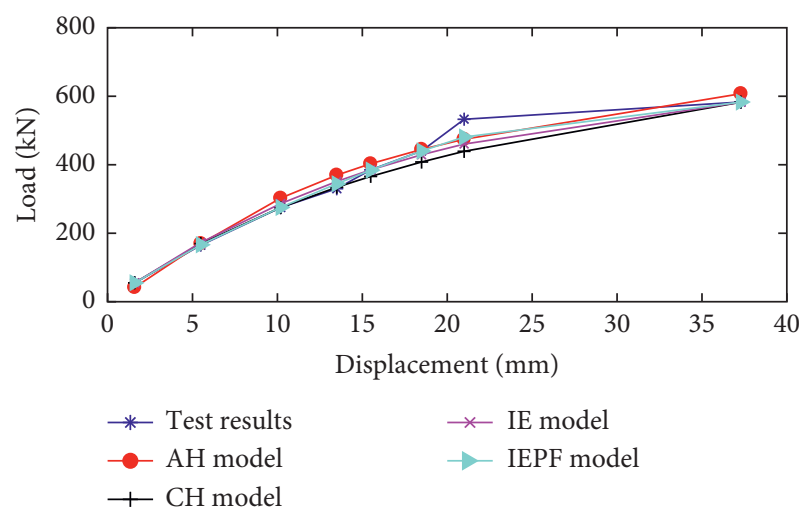

Figure 10: Comparison of each model with the test data from $D_{2}$. 
TABle 18: Accuracy of each model for example 4.

\begin{tabular}{lcccc}
\hline Model & $\mathrm{SSE}_{D 1}$ & $\mathrm{SE}_{D 1}$ & $\mathrm{SSE}_{D 2}$ & $\mathrm{SE}_{D 2}$ \\
\hline $\mathrm{AH}$ & $4.36 \times 103$ & 22.02 & $6.90 \times 103$ & 29.36 \\
$\mathrm{CH}$ & $8.48 \times 103$ & 30.69 & $1.02 \times 104$ & 35.78 \\
$\mathrm{IE}$ & $1.14 \times 104$ & 35.67 & $6.00 \times 103$ & 27.40 \\
$\mathrm{IEPF}$ & $3.25 \times 103$ & 19.01 & $2.91 \times 103$ & 19.08
\end{tabular}

TABle 19: Stability of each model for example 4.

\begin{tabular}{lcccc}
\hline Model & $\mathrm{SSPE}_{D 1}$ & $\mathrm{SPE}_{D 1}$ & $\mathrm{SSPE}_{D 2}$ & $\mathrm{SPE}_{D 2}$ \\
\hline $\mathrm{AH}$ & 0.47 & 0.23 & 0.10 & 0.11 \\
$\mathrm{CH}$ & 0.11 & 0.11 & 0.04 & 0.07 \\
$\mathrm{IE}$ & 0.23 & 0.16 & 0.03 & 0.06 \\
$\mathrm{IEPF}$ & 0.06 & 0.08 & 0.01 & 0.04 \\
\hline
\end{tabular}

TABLE 20: Ultimate bearing capacity prediction for example 4.

\begin{tabular}{lcccc}
\hline Model & Prediction $_{D 1}$ & Error $_{D 1}(\%)$ & Prediction $_{D 2}$ & Error $_{D 2}(\%)$ \\
\hline $\mathrm{AH}$ & 1341.9 & 118.2 & 1147.1 & 96.76 \\
$\mathrm{CH}$ & 1134.7 & 84.50 & 1007.9 & 72.88 \\
$\mathrm{IF}$ & 726.88 & 18.19 & 654.56 & 12.27 \\
$\mathrm{IEPF}$ & 617.51 & 0.41 & 589.68 & 0.87 \\
\hline
\end{tabular}

data. However, it is difficult to define the physical meaning of each parameter in this stage and to obtain field test data considering the economic challenges and implementation limitations associated with in situ pullout tests. Thus, the next phase is to predict the ultimate bearing capacity of a bolt based only on the bolt geometry, the material properties of the bolt, the specific geological conditions, and the construction situation.

\section{Conclusions}

The ultimate bearing capacity is the key parameter for bolt design in underground reinforcement engineering. In this study, the IEPF model was presented to investigate the relationship between the load and displacement of bolts and to predict the ultimate bearing capacity of bolts in pullout tests. Partial pullout test data were used to solve for the unknown parameters in the model.

By comparing the resulting accuracy and stability with those of other models, the simulation curves and ultimate bearing capacity predictions produced by the IEPF model were found to be consistent with pullout test results from the literature. In practise, the IEPF model can help engineers gain a better understanding of the load-displacement relationship and predict the ultimate bearing capacities of bolts.

\section{Data Availability}

The data used to support the findings of this study are available from the corresponding author upon request.

\section{Conflicts of Interest}

The authors declare that they have no conflicts of interest.

\section{Acknowledgments}

This research was supported by the Fundamental Research Funds for the Central Universities (2019B07914) and the National Natural Science Foundation of China (Grants nos. 51678217, 51378176, and 51808193). This support is gratefully acknowledged.

\section{References}

[1] W. Yu, H. Yang et al., "Non-destructive testing on anchorage quality of hollow grouted rock bolt for application in tunneling, lessons learned from their uses in coal mines," Tunnelling and Underground Space Technology, vol. 93, Article ID 103094, 2019.

[2] J. Zhang, T. Feng, J. Yang, F. Yang, and Y. Gao, "Upper-bound stability analysis of dual unlined horseshoe-shaped tunnels subjected to gravity," Computers and Geotechnics, vol. 97, pp. 103-110, 2018.

[3] J. Zhang, Y. Liang, and T. Feng, "Investigation of the cause of shield-driven tunnel instability in soil with a soft upper layer and hard lower layer," Engineering Failure Analysis, vol. 118, Article ID 104832, 2020.

[4] J. Zhang, T. Feng, F. Zhang, and W. Li, "Experimental study on improvement of seawall filler materials composed of sea sand and sea mud," Marine Georesources \& Geotechnology, vol. 38, no. 2, pp. 193-203, 2020.

[5] L. Jiang, P. Kong, J. Shu, and K. Fan, "Numerical analysis of support designs based on a case study of a longwall entry," Rock Mechanics and Rock Engineering, vol. 52, no. 9, pp. 3373-3384, 2019.

[6] L. Jiang, Q. Wu, Q. Wu et al., "Fracture failure analysis of hard and thick key layer and its dynamic response characteristics," Engineering Failure Analysis, vol. 98, pp. 118-130, 2019.

[7] H. Y. Fu, Z. M. Jiang, and H. Y. Li, "Physical modeling of compressive behaviors of anchored rock masses," International Journal of Geomechanics, vol. 11, no. 3, pp. 186-194, 2010.

[8] A. Starkey, A. Ivanovic, A. A. Rodger, and R. D. Neilson, "Condition monitoring of ground anchorages by dynamic impulses: granit system," Meccanica, vol. 38, no. 2, pp. 265-282, 2003.

[9] M. Cao, L. Cheng, Z. Su, and H. Xu, "A multi-scale pseudoforce model in wavelet domain for identification of damage in structural components," Mechanical Systems and Signal Processing, vol. 28, pp. 638-659, 2012.

[10] H. F. Thurner, "Boltometer-instrument for non-destructivetesting of grouted rock bolts," in Proceedings of the 2nd International Symposium on Field Measurements in Geomechanics, Sakurai, Ed., vol. 26, pp. 135-143, Elsevier, Rotterdam, Netherlands, December 1988.

[11] C. S. Zhang, D. H. Zou, and V. Madenga, "Numerical simulation of wave propagation in grouted rock bolts and the effects of mesh density and wave frequency," International Journal of Rock Mechanics and Mining Sciences, vol. 4, no. 43, pp. 634-639, 2006.

[12] Y. Chen, "Experimental study and stress analysis of rock bolt anchorage performance," Journal of Rock Mechanics and Geotechnical Engineering, vol. 6, no. 5, pp. 428-437, 2014.

[13] L. B. Martín, M. Tijani, H. H. Fauozi et al., "Assessment of the bolt-grout interface behaviour of fully grouted rockbolts from laboratory experiments under axial loads," International Journal of Rock Mechanics and Mining Sciences, vol. 63, pp. 50-61, 2013. 
[14] U. M. R. Karanam and S. K. Dasyapu, "Experimental and numerical investigations of stresses in a fully grouted rock bolts," Geotechnical and Geological Engineering, vol. 23, no. 3, pp. 297-308, 2005.

[15] B. H. Tekle, A. Khennane, and O. Kayali, "Bond behaviour of GFRP reinforcement in alkali activated cement concrete," Construction and Building Materials, vol. 154, pp. 972-982, 2017.

[16] T. Wu, C. Cao, J. Han et al., "Effect of bolt rib spacing on load transfer mechanism," International Journal of Mining Science and Technology, vol. 27, no. 3, pp. 431-434, 2017.

[17] T. Ahmet, "Effect of mineral admixture types on the grout strength of fully-grouted rockbolts," Construction and Building Materials, vol. 145, pp. 376-382, 2017.

[18] M. Cai, "Principles of rock support in burst-prone ground," Tunnelling and Underground Space Technology, vol. 36, pp. 46-56, 2013.

[19] L. K. Chen, "Present status and development of ground anchorages," China Civil Engineering Journal, vol. 34, no. 3, pp. 7-12, 2001.

[20] X. S. Zhuang, R. G. Zhu, and X. Zhao, "Study on the limit analytic method determinate soil layer anchor supporting capacity," Sichuan Building Science, vol. 31, no. 4, pp. 76-77, 2005.

[21] J. Nemcik, S. Ma, N. Aziz, T. Ren, and X. Geng, "Numerical modelling of failure propagation in fully grouted rock bolts subjected to tensile load," International Journal of Rock Mechanics and Mining Sciences, vol. 71, pp. 293-300, 2014.

[22] L. Zhao, "Uplift mechanism of bolt and its application in selfanchored loading test technology of pile foundation" Ph.D. thesis, Hunan University, Changsha, Hunan, China, 2007.

[23] J. P. Jiang, G. Y. Gao, and W. B. Liu, "Modified hyperbolic model describing q-s curves of squeezed branch pile," Journal of Basic Science and Engineering, vol. 18, no. 6, pp. 999-1009, 2010.

[24] F. Tu, F. Q. Chang, and X. P. Li, "Predicting ultimate bearing capacity of single cement mixing pile by exponential and hyperbola methods," Journal of Fujian University of Technology, vol. 4, no. 1, pp. 21-23, 2006.

[25] P. Bai, Q. L. Wei, and N. Wang, "Research on ultimate uplift capacity of tension piles of uniform section based on prediction of power function model," Grain Distribution Technology, vol. 6, pp. 9-13, 2010.

[26] X. N. Wang, R. Ye, and F. J. Zhou, "Proposals for the selection of failure criteria in soil float-resisting achor rod test," Journal of Geological Hazards and Environment Preservation, vol. 12, no. 3, pp. 73-77, 2001.

[27] M. G. Liu, Y. B. Yang, X. H. Yue, and Q. Li, “The prediction method of ultimate resistance capacity of bolt base on grey theory," Chinese Journal of Underground Space and Engineering, vol. 2, no. 6, pp. 1044-1048, 2006. 